\title{
Hubristic Manipulation and Caleb(an) Resistance in Ex Machina
}

\section{* 1 Talaat Farouq Mohamed, 2 Ashraf Said Qutb Metwalli, 3 Mohamad El-Sebaey Ibrahim Zayed, 4 Samah Thabet Sayed Thabet}

Assistant Professors at College of Sciences and Arts, Jouf University, KSA (Affiliation 1, 2, 3, 4)

Faculty of Languages and Translation, Al-Azhar University, Egypt (Affiliation 1, 2, 3)

Faculty of Arts, Cairo University (4)

*Corresponding Author (tffarrag@ju.edu.sa)

\begin{abstract}
This paper investigates the literary/psychological manifestations in Ex Machina through analysing hubristic attitudes and morally driven resistance to unbridled hegemony. It traces the ways Garland externalized the conflict between human unethical superego and humane alter ego. The modern man's aspiration to play god through developing a fully sentient AI droid is critically discussed in comparison with the Prospero-Caliban conflict in Shakespeare's The Tempest as well as Ovid's Pygmalion. The power game played throughout the drama is also probed in terms of Nathan's manipulation of Caleb, Caleb's resistance to Nathan's hegemony and Ava's eventually successful counter-manipulations. Besides, it attempts to explore the potentials of psychorobitc art as cinematically featured.
\end{abstract}

Keywords

Ex Machina, Psychorobitc Sentience, Hubris, Empathy and Resistance

Article Received: 10 August 2020, Revised: 25 October 2020, Accepted: 18 November 2020

\section{Introduction}

Alex Garland's directorial debut part-thriller part romance, Ex Machina (2014), is a reflexive [1] story about a young coder, Caleb Smith (Domhnall Gleeson), who works at the world's top Google/Facebook-like internet company, known as Bluebook, and who - winning a lotterylike competition - is awarded a week-time visit to the CEO's estate/research facility. Reaching there, Caleb discovers that the tech-Mogul CEO, Nathan Bateman (Oscar Isaac), has developed a nearly sentient, self-aware droid, Ava (Alicia Vikander), and wants him to run a modified version of a Turing Test to her and see if she can pass the test. The drama intensifies through the brainstorming, question-raising Caleb-Nathan/Caleb-Eva dialogues. Interestingly, Ava manipulates Caleb well into helping her escape from the prison-like facility but only after killing Nathan and leaving Caleb to die locked down in a glass box-room.

The movie can be read in several ways, either as an exploration of the future of dystopian future of humans at the hands of their created sentient AI robots; as a critique of stereotyped gender representation of women under a male god-like patriarchy; as a philosophical inquiry into
AI moral agency; or as an investigation of human consciousness as projected onto a humanoid robot that happens to be a female figure, just like Ovid's Galatea or Fritz Lang's Maria in his 1927 Metropolis (which seems to be a major inspiration for Garland's movie). The focus of the present article however is to investigate the use of $\mathrm{AI}$ as a sheer medium or an objective correlative towards an enhanced understanding of human emotions and desires and also their imperfection. Still, we will first zoom in on Caleb's character as a foil to Ava, in the sense of being tested by Nathan, or as a human proxy manipulated by Ava to overpower her creator Nathan and then carelessly abandoned to meet his inevitable doom, not quite unlike his egoistically overambitious peer, Nathan.

In this light, Ex Machina can be viewed as a psychoanalytical and political narrative, given that Alex Garland himself was the son of a psychoanalyst and a political cartoonist. [2] Accordingly, it represents a reflection on robotoid, tech-savy humans of our technophilic age and the intricacies of their alternate waves of hegemonic desires and counter-hegemonic resistance; something like a subversive version of Alex Proyas' I, Robot (2004) and close to Ann Leckie's The Imperial Radch Trilogy (2013-15). From a 
cultural perspective, there is room in Ex Machina to trace psychological and literary intricacies of the human psyche as embodied in the longstanding myth of a life-given god-like machine that is invested in solving a manifestly unsolvable climax.

Literarily speaking, the title of the movie itself derives - besides the computer game Deus Ex (1999) and the Latin theatrical device 'Deus ex Machina' or god-from-the machine - or from the other phrase 'Homo ex Machina', that is to think human out of a machine.[3] The phrase "DEUS EX MACHINA" even appears as a title of the folder detected by Caleb on Nathan's computer and it contains a list of subfolders, having a girl name (JASMINE, KATYA, JADE, LILY, AMBER, KYOKO, and AVA). This list of "godsfrom-machines" AI droids reminds us of Horace's warning against the unnecessary use of such theatrical device as this threatens to thwart the entire drama, which eventually happens (at least for Nathan).

The movie embodies an interplay between the 'Deus ex Machina' and 'Homo ex Machina', with the first plot centering on Nathan-Caleb relationship while the second hinged on CalebAva relationship. Here, the two tropes will be carefully analyzed; first the idea of robotoid humans' sense of moral agency under a threatening commercializing environment and humanoid robots' sentience or capacity to subjectively experience human feelings, in turn bridging the gap of difference between them and humans and raising man closer to a much-desired god-like status, has been the core discussion, which is pressing in today's technophilic world. In his article, "Can robots have emotions?" Dylan Evans traces such theme of robots capable of experiencing human feelings through sci-fi movies like, A Space Odyssey (2001), Blade Runner (1982) and Bicentennial Man (1999).

Just like Robin Williams in the latter, Ava comes closer to 'experiencing the full range of human feelings,' [4] though this evolutionary stage has a price that its creator himself had to pay for by losing his own life. This dramatic downfall of a protagonist who features at the very beginning as an invincible, god-like tech-Mogul recalls a long history of encounters between a hegemonic sovereign and a resistant 'subaltern', be it a machine-like human (Caleb) or a humanlike machine (Ava). We will thus investigate this line of power game (mental colonization and resistance to it) through focusing first on NathanCaleb relationship as a manifestation of Nathan's God-like patriarchy and then Nathan-Caleb/Ava relationship as a representation of what might be termed as 'counter-colonial resistance'.

\section{Hubris as Nathan's Tragic Flaw}

Nathan's tragic flaw was his hubristic attempt to defy or alter natural order. This hubristic or god-like inclination indicates a psychological illness that is detected by Caleb. Such lust for godhead is almost like Pygmalion's lust for Galatea, given that the idea of sexualization itself was employed in Garland's movie, "Why did you give her sexuality? An AI doesn't need a gender. She could have been a grey box" Caleb is wondering. Here, Nathan insists, "if I've created a conscious machine, I'm not man. I'm God" (Ex Machina 52) [5] and repeats later "See? I really am a God." (87) Here springs the significance of Caleb's role in helping Ava escape and in resisting Nathan's moral perversion.

In his Norwegian far-off retreat on the island, with its claustrophobic facility, which bears echoes of Shakespearean Bermuda in The Tempest or the isle of the devils, Nathan is keen to make a show a god-like attitude from the very beginning. [6] Yet, like Shakespeare's Caliban, Caleb conspires with Ava to escape from the island just as Caliban conspired with Trinculo and Stephano to take control from Prospero by killing him. Caleb, like his predecessor, Caliban, is anxious about the unethical complexities of civilization - here AI technology - as detrimental to human moral compass, though he himself was not disgruntled against being trapped by social media networks into box-like isolated islands far from physical human communication.

The socially trapped and vulnerable Caleb, "with no family ... no girlfriend", thus turns into an optimum target for Nathan's experimentation. He was like a Guinee Pig about whom nobody would care about in case experimentation goes wrong and above all, because he - according to Nathan - is "a good kid ... with a moral compass". (105) It was through the help of this 
human component (Caleb) in the Turing Test that the machine-creator, Nathan, was overcome. But just like Cornel Kurtz (Marlon Brando) in Apocalypse Now (1979), Nathan's inevitable doom largely reflects the Macbethan 'horror that cannot be named'.

The sheer apocalyptic effect in the narrative comes as a price for unconscientious manipulation which is a manifest theme in the movie. Caleb seems to be well manipulated even before he comes to the island, as the movie opens with him identified through facial recognition marking software. We even know about his dead family and his malleability and keenness to impress his superiors at an early stage. All these characteristics represent his vulnerability and in turn his being an exemplary component in Nathan's modified version of the Turing Test.

Here, the psyching part plays out, though it was only discovered late by Caleb, "Damn. Can't believe I've been missing this. I was so psyched to be coming here" (emphasis added). When Caleb refers to the experiment he had in college, which was called "Mary in the black and white room". (Ex Machina 67) It was about a color specialist scientist who knows everything about colors, including their wavelengths and neurological effects, and yet she received the world only in black and white through her black and white monitor and in her black and white room, in which she was kept throughout her life.

So, all her knowledge about real colors and the world is second-hand. Mary's only real experience of the world occurs when she walks out of the room and sees the blue sky for the first time. Such is the difference between a computer mind and a human mind. It is a gap between recognition of real and vivid colors and knowledge of colors received only in black and white, or as Caleb said; learning what it feels like to see colors is not an experience that can be taught or conveyed.

Hence, he felt morally bound to help Ava enjoy a first-hand experience of the outside world with its real, not 'virtual', colours. For him, Nathan's hegemonic control over Ava, Kyoko and the rest of earlier disembodied prototypes is unethical. Not only that, but he also helps in reshaping our view of the other (Ava) through developing a sort of romantic attachment to her.

Caleb feels that the psychological dilemma results from the Nathan's self-willed physical and psychological isolation, which makes him already tipped over the edge. Nathan's near paranoid, near alcoholic and even almost schizoid attitude tempts him to think of himself as a god in a hubristic manner. But still that self-assumed god cannot escape the idea that he needs others, like Caleb, to fulfil his plans.

How come a god-like figure fall inebriated all night and just sober up all day. This dichotomy hints at his flawed personality and emotional instability. It could also hint at a traumatic past that he could never recover from. That possible harmful experience he may have gone through left its mark on him and whetted his appetite to take control of the world around through manipulative deceit. How come a god-like figure fall inebriated all night and just sober up all day. This dichotomy hints at his flawed personality and emotional instability!

His personality disorder that further surfaces through dialogues with Caleb encourages the latter to play a line of resistance throughout. $\mathrm{He}$ always offers logical counterarguments to Nathan's premises. This resistant bent intensifies as he develops stronger affection towards Ava and as he comes upon footage of earlier android models (in the process of) being dismantled. He also felt disturbed upon watching a footage of Ava's two predecessor prototypes taught to draw, even though they were headless. This footage shocked him back to his senses about Ava's machine nature. In any normal situation, his exclamation, "Jesus Christ!" and his panicked facial reaction upon watching the footage would seem an overreaction.

It could also indicate his developing empathy towards AI robots in general. Another interesting aspect, that is sometimes read as an indirect critique of racism against the blacks is that the Caucasian female prototype robot could walk while the black one was dragged. Perhaps Caleb could read that as an indication of Nathan's racism, especially if we recall their argument 
about the colour of a sexualized robot and whether he would feel inclined to a black Gray box.

Nathan's personality disorder is also exposed through his conversations with Caleb, and this encourages the latter to play a line of resistance throughout. Caleb always offers logical counterarguments to Nathan's premises. This resistant bent intensifies as he develops stronger affection towards Ava and as he comes upon footage of earlier android models (in the process of) being dismantled.

Here comes the legacy of wise quotes, for which Caleb shows a skill, when he counter's Nathan's claim for godhead. He immediately quotes $\mathrm{J}$. Robert Oppenheimer's famous phrase, "I am become death, the destroyer of worlds." Here, Caleb is knelling a bell of wisdom and caution about the potential destructive powers at hand. He also foreshadows the possible tragic end that is about to sweep Nathan's microcosmic world of unethical AI-related research. He frequently showed reservations against the way Nathan treated both Ava and Kyoko, which for him seemed unjustifiable.

When he showed interested in knowing the mechanism of Ava's developing semantic and syntactic, and also reflexive, capacity, he seemed to be more interested in exploring such capacity himself, even if it means doing that away from Nathan.

In this sense, he worked on botching Nathan's plans of destroying earlier prototypes, including Ava, and developing a new model of higher functions or full sentience.

Still, Caleb has his own tragic pitfalls too that shows in his overconfidence in his flirtations with Ava, which she describes as micro-expressions, including the way he blushes and fixes his eyes on her eyes and lips and the way he held her gaze. (Ex Machina 56-7) Likewise, his overconfidence in his talents reflects his dilemma as much as it foreshadows his eventual doom, as the movie closes with echoes of his pathetic screams for help as Ava appropriates his seat on the helicopter on the way back home. His overconfidence is even fed by Nathan who used to praise his power of quoting wise statements when addressing dilemmatic situations, "You've got a way with words there, Caleb. You're quotable." (26)

What augments the intensity of the drama about Caleb is that he unwittingly presages, through Ava's comic riposte, that she is manipulating him, "It was a play on words, and a play on me" (46) No doubt that Caleb is played both ways, first by Nathan and then by Ava, an aspect hinted at earlier in the movie when he was. This is quite apparent from the very moment he approaches the gate of Nathan's retreat, when his keycard is automatically produced for him with a photograph of his him looking "comically surprised" (Ex Machina 9) He is even denied a second ID-photo making attempt.

He was driven to the extent of doubting his own humanness. Upon seeing Kyoko pull off her silicone skin and uncover her honeycomb mesh and robotic form, he - stunned and transfixed with doubt - cuts his own forearm with a tiny razor blade to make sure that he is human and not robot. He sighs in relief once he sees his blood droplets run out. This is a moment for Caleb-like audience to ponder on their reflection in the mirror and see if they can retain their moral compass and avoid the near autistic behavior imposed by AIdominated modern life.

Caleb's help to Ava against the will of his boss may also reflect an ambition on his part to see how far the experiment would go, especially for Ava. He is eager to explore how far their relation could go, giving room for application of possible coding improvements to her. It may also reflect an ambition on his part to see how far the experiment would go, especially for Ava. Meanwhile, he is eager to explore how far their relation could go, giving room for application of possible coding improvements to her.

Ava used Nathan's trick of tearing up Caleb's picture in convincing the latter that she had feelings for him and that she is in danger and needs to be saved. Unwittingly, Caleb took the bait and thus (as a huma) failed the test of discriminating true love from emotional manipulation. Ava's question - that seems to have provoked Nathan - "Is it strange to have made something that hates you?" Perhaps Ava meant to push Nathan into tearing the picture by asking him 
that question. And in this way, she would have not only outwitted but even - manipulated both Nathan and Caleb.

Nathan is finally hoisted with his own petard and his awareness could not prevent his murder at the hands of his created AI androids. Ava only acted according to the escape command coded into her program by Nathan, regardless of the means.

\section{Caleb(an) Resistance and the Impact of Moral Agency}

Caleb is carefully selected by Nathan to participate in the test because of his human vulnerability. Ironically, this vulnerable spot in his character comes to be a means to Nathan's own downfall. Though manipulated by Ava, still he makes a moral choice to foil Nathan's unethical plans and that choice costs him his life. In this sense, he is a near Faustus who also meets his doom through contracting with Mephistophelean agent, Nathan, though he had a good grain in him. It is true that he was skilfully manipulated by Eva to the point of falling in for her and thus facilitating her escape. This is confirmed by Nathan through his remark that "Eva was in a mousetrap" and had all possible means to get out of that trap; "she would have to use imagination, sexuality, self-awareness, manipulation.” (104)

That is the way Caleb was tested. It is all algorithmic calculations on Eva's part, but this is not the case with Caleb. While he started to trust and empathize with her, she kept maneuvering. When he asked her to draw something specific so that he could measure her ability to create a drawing of her free choice, she could not. Yet, she managed to evade the question and struck an emotional tone that won Caleb's emotion, "Do you want to be my friend" (37). He took the bait and became the test object himself, simply because he had an emotional vulnerability given his tragic familial history. The human 'empathy' integrated in Ava's programming by Nathan did not exceed the level of understanding and manipulating the experiences of others, being no more than a fake verbal empathy. Caleb's empathy, on the other hand, is genuine that was why to chose to take Ava's side regardless of the consequences.
Ava, on the other hand, used Nathan's trick of tearing up Caleb's picture in convincing the latter that she had feelings for him and that she is in danger and needs to be saved. Unwittingly, Caleb took the bait and thus (as a huma) failed the test of discriminating true love from emotional manipulation. Ava's question - that seems to have provoked Nathan - "Is it strange to have made something that hates you?" (Ex Machina 104) Perhaps Ava meant to push Nathan into tearing the picture by asking him that question. And in this way, she would have - not only outwitted but even - manipulated both Nathan and Caleb.

Nathan is finally hoisted with his own petard and his awareness could not prevent his murder at the hands of his created AI androids. Ava only acted according to the escape command coded into her program by Nathan, regardless of the means. She had no scruples to manipulate both Caleb and then Kyoko at ease and to carelessly leave them behind on her way out, just as she cared less about her former prototypes.

She also took advantage of her superior artificial intelligence to that of Kyoko, of Caleb's vulnerability and of Nathan's inebriation. That is what she is built for, manipulation of others. This also hints at the possibility of her outsmarting the helicopter pilot and convincing him to take her back (forward) to the real world, although he is supposed to be expecting Caleb.

Here lies the difference between Ava and Caleb, it is a difference between the moral and the amoral, or the difference between the human and the nonhuman. It is a clear message for humanity to maintain their moral compass.

One final points is to address the intricacies of a possible psychologically imbalanced robots or robots coded wrongly from a psychological perspective. This point can be discussed through the portrait of Ava as a higher-intelligence AI android. Psychologically equipped robots are the main target of AI developers in modern times. As humans, we pay too much attention to the psychological welfare of individuals as well as of society as a whole. That is why we try to project that psychological element on AI androids. When people ask that simple question, 'does this or that 
robot have consciousness?', they just reflect their concern as humans over the uncalculated outcomes of potentially damaging robotic behavior. Piercosma Bisconti Lucidi remarks in his thesis, "The Social Robot as a Significant Other - Meaningful Relations in Human-Robot Interactions" that "Human-robot interactions are problematic both for the ethically correct modalities of these relations, and because they raise in a new field, that of robotics, old problems of philosophy such as the definition of consciousness, knowledge, empathy, emotion, ethic, intersubjectivity, moral behavior. [7]

Ava is developed as a fully conscious AI that has the ability of syntactic as well as semantic manipulation; a feature that enables her to impress the genius young coder, Caleb and makes him align with her against her developer in her escape attempt. This is because she uses a very persuasive language that amazes him. His sympathy with her comes as a result of his miserable childhood memories, of course beside her ability to psychologically direct his decisions. She displays great skills of act the victim and thus win his sympathy.

Likewise, Kyoko's representation of a nearly female traumatic experience of rape at the hands of Nathan, evokes resonances of Ovid's

\section{Conclusion}

Ex Machina represents a complex work of art that is open to multiple interpretations. This is due to its deep artistic, moral and philosophical perspectives. One of its core tropes is the drama of human downfall due to ungodly hubris. In this sense, it echoes Shakespeare's The Tempest and of Ovid's Pygmalion. [8] This subtle adaptation of both myth and artistic tradition augments its multi-interpretive tenor. As in The Tempest, Nathan, a modern Prospero, assumed he could play god on his devilish isle, creating an AI android that can use imagination, sexuality, selfawareness, empathy, manipulation". While this image of Nathan raises questions about the morality crisis besetting the work of AI developers, it also invites us to consider how far the modern community can preserve human values and how AI developer can align with those
Metamorphosis. Kyoko is always silent in the movie, and the audience have the feeling that is being raped by Nathan as a sheer sex toy or gray box. This image aligns with the modern commodifying, commercializing and sexualizing attitude towards women in the increasingly globalized world.

This also typically alludes to the myth of Ovid's Philomel who was raped by King Tereus and had her tongue cut to ensure she would not convey the traumatic story of her rape to anyone else. At the end, she got her vengeance through her sister Procne; the wife of Tereus. Ex Machina echoes this myth as represented in the victimization of Kyoko by Nathan. The mythical cut of the tongue compares to Kyoko inability to speak. As is the case with Philomel, Kyoko gets assistance from her sister-like Ava in the murdering of Nathan at the final scene.

Masculine victimization of women seems to be persistent over ages even though in different forms. Kyoko represents that type of psychologically and physically submissive females contrary to Ava who represents a challenge to patriarchy through her overambitious endeavors to break free from the prison-like research facility.

human values. Caleb, a modern Caliban, managed to thwart Nathan's unethical aspirations and helped the humanoid female droid escape his hegemonic grip.

\section{References}

[1] For more information on the reflexivity of the movie's narrative vision, see Brian R. Jacobson's (2016) "Ex Machina in the Garden”, Film Quarterly 69.4: 23-34.

[2] Leith, Sam (2004). "It cuts both ways". The Telegraph. Retrieved January 29, 2021, from https://www.telegraph.co.uk/culture/books /3618820/It-cuts-both-ways.html 
[3] Kohler, Alaric, (2010). "To Think Human out of the Machine Paradigm: Homo Ex Machina". Integr. psych. behav. 44, 39-57. https://doi.org/10.1007/s12124-010-9113-z

[4] Evans, Dylan (2021). "Robots have feelings too." Nature, vol. 437, no. 7055, 2005, p. 35.

[5] Garland, A. (2014). Ex Machina. A24. Retrieved January 29, 2021, from https://www.scriptslug.com/assets/uploads /scripts/ex-machina-2015.pdf

[6] Shakespeare, William, 1564-1616. (1958). The Tempest. Cambridge: Harvard University Press.

[7] Bisconti Lucidi, Piercosma. (2018) "The Social Robot as a Significant Other Meaningful Relations in Human-Robot Interactions" (Master's Thesis). Available from ResearchGate. Retrieved January 29, 2021, from (10.13140/RG.2.2.10620.90242).

[8] James, P. (2011). Ovid's myth of Pygmalion on screen: In pursuit of the perfect woman. London: Continuum. 